\title{
Simultaneous Determination of Cobalt (II) and Nickel (II) By First Order Derivative Spectrophotometry in Micellar Media
}

\author{
RAJNI ROHILLA and USHA GUPTA* \\ Department of Chemistry, \\ Punjabi University Patiala, Punjab, India. \\ *ushagupta_doc@yahoo.co.in
}

Received 31 October 2011; Accepted 01 February 2012

\begin{abstract}
A first-derivative spectrophotometry method for the simultaneous determination of Co (II) and Ni (II) with Alizarin Red S in presence of Triton $\mathrm{X}-100$ is described. Measurements were made at the zero-crossing wavelengths at $549.0 \mathrm{~nm}$ for Co (II) and $546.0 \mathrm{~nm}$ for Ni (II). The linearity is obtained in the range of $0.291-4.676 \mu \mathrm{g} / \mathrm{ml}$ of $\mathrm{Ni}$ (II) and $0.293-4.124 \mu \mathrm{g} / \mathrm{ml}$ of Co (II) in the presence of each other by using first derivative spectrophotometric method. The possible interfering effects of various ions were studied. The validity of the method was examined by using synthetic mixtures of Co (II) and Ni (II). The developed derivative procedure, using the zero crossing technique, has been successfully applied for the simultaneous analysis of $\mathrm{Co}$ (II) and $\mathrm{Ni}$ (II) in spiked water samples.
\end{abstract}

Keywords: Cobalt (II), Nickel (II), Alizarin Red S, Triton X-100, derivative spectrophotometry.

\section{Introduction:}

Nickel and cobalt metals are significant for environmental surveillance, food control, occupational medicine, toxicology and hygiene. Cobalt alloys are used in some industrial products because of their sufficient hardness and resistance against oxidation at high temperatures. Cobalt-60 is used as an efficient radioactive tracer and an anti-cancer treatment agent in medicine. Vitamin B12 (cyanocobalamin) is important for biological activities1. Even though cobalt is not considered to be as toxic as most of the heavy metals, it is an equally harmful element. Toxicological effects of large amounts of cobalt include vasodilatations, flushing, and cardiomyopathy in humans and animals.

Nickel is the metal component of the enzyme urease and as such is considered to be essential to plants and some domestic animals. Nickel can cause allergic reactions and that certain nickel compounds may be carcinogenic 2.The determination of cobalt and nickel in 
various samples in which it is found at low levels requires the use of sensitive and selective procedures.

Among various methods that have been developed for the simultaneous determination of nickel and cobalt are Atomic absorption spectrophotometry (AAS) using Flame atomic absorption spectrophotometry (FAAS) 3 or Electrothermal atomization Atomic absorption spectrophotometry (ETAAS)4-6, high performance liquid chromatography7-10, chelation ion chromatography11-12, electroanalytical techniques13-15,Neutron activation analysis (NAA)6, X-ray fluorescence (XRF)17-18, and spectrophotometric methods19-22.UVVisspectrophotometric analytical procedures are most widely used for the simultaneous determination of metals .The obvious reasons being experimental simplicity, rapidity and the wide applicability of these procedures. In many cases traditional techniques are not suitable for simultaneous determination because, the absorption spectra overlap and are not suitable for simultaneous quantative analysis. Derivative spectrophotometry has been an extremely useful technique for the simultaneous determination of binary mixtures.

Derivative spectrophotometry in the $\mathrm{UV}-\mathrm{V}$ is region is a useful technique for determining the concentration of a single component in binary and ternary mixtures of compounds whose spectra shows considerable overlap. It is possible to measure the absolute value of the derivative of the sum curve at an abscissa value (wavelength) corresponding to a zero-crossing of one of the components in the mixture. This is termed as zero-crossing measure and can be applied to the first derivatives. The zero-crossing derivative spectrophotometry mode allows the resolution of binary mixtures of analytes by recording their derivative spectra at wavelengths at which one of the components exhibits no signal. Zero-crossing measurements for each component of the mixture are therefore the sole function of the concentration of the others.

This paper reports a simple, sensitive and highly selective first order derivative spectrophotometry method for simultaneous determination of nickel and cobalt. The method is based on the formation of the complexes of $\mathrm{Ni}$ (II) and Co (II) with Alizarin Red $\mathrm{S}$ in Triton X-100 micellar media.

\section{Experimental:}

\section{Apparatus:}

UV-visible absorbance spectra were recorded on a Shimadzu UV-1800 scanning spectrophotometer. Digital century pH-meter CP 901 with a combined glass electrode was used for $\mathrm{pH}$ measurements.

\section{Reagents:}

All the reagents used were of analytical reagent grade unless otherwise stated and double distilled water was used throughout the experiment. A $0.1 \%(\mathrm{w} / \mathrm{v})$ solution of Alizarin Red S in doubly distilled water was prepared. Stock solution of $\mathrm{Ni}$ (II) and $\mathrm{Co}$ (II) $\left(1 \times 10^{-2} \mathrm{M}\right)$ were prepared. A buffer solution of $\mathrm{pH} 7.0$ was prepared from ammonia and ammonium chloride at appropriate concentration and 1\% Triton X-100 solution was prepared in hot distilled water.

\section{General Procedure:}

A $2.0 \mathrm{~mL}$ volume of buffer solution of $\mathrm{pH} 7.0,1.0 \mathrm{~mL}$ of $(0.1 \%)$ ARS solution, an appropriate volume of Co (II) and $\mathrm{Ni}$ (II) and $2.0 \mathrm{~mL}$ of Triton X-100 were added to a 10 $\mathrm{mL}$ standard flask and final volume of the solution was adjusted with distilled water. The 
absorbance of the mixtures were measured in the wavelength range $480.0-640.0 \mathrm{~nm}$ against reagent blank solutions in the first derivative mode.

\section{Results and Discussions:}

\section{Absorption Spectra:}

The normal absorption spectra of Co(II)-ARS complex and Ni(II)-ARS complex in the presence of Triton X-100 showed the absorbance maxima at $549.0 \mathrm{~nm}$ and $546.0 \mathrm{~nm}$, respectively (Figure 1). Since the spectral bands of complexes overlap, the determination of cobalt and nickel in their mixtures by zero-derivative is frequently impossible. By using derivative spectrophotometry, we could analyse these samples simultaneously.

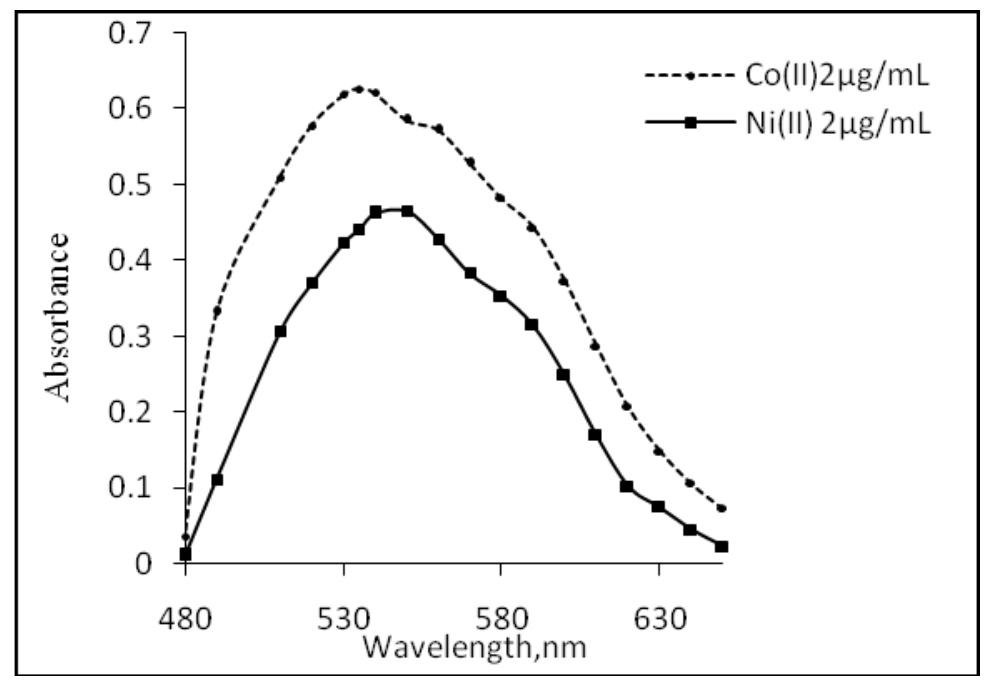

Figure 1. Absorption spectra of mixture of Co (II) and $\mathrm{Ni}$ (II) with $1.0 \mathrm{~mL}$ ARS (0.1\%) solution and $2.0 \mathrm{~mL}$ Triton $\mathrm{X}-100(1 \%)$ at $\mathrm{pH} 7.0$.

\section{Effect of $p H$ :}

Absorbance for both complexes was studied over a wide range of $\mathrm{pH}$ from $2.0-9.0$. The studies showed that the absorbance was maximum in the $\mathrm{pH}$ range $6.0-7.0$ for both complexes (Figure 2). Hence, further studies were carried out at $\mathrm{pH}$ 7.0.

\section{Nature of Surfactant:}

The effect of nature and concentration of different surfactants such as Sodium lauryl sulphate (SLS), Cetyltrimethylammonium bromide (CTAB), Cetylpyridinium bromide (CPB), Triton X-100, Tween-80, and Tween-20 on the absorbance of Ni (II)-ARS and Co (II) -ARS complexes was studied and it was observed that complex formation is faster, stable and maximum in presence of Triton X-100, so it was selected as micellizing agent for further studies. The effect of concentration of Triton X-100 on sensitivity of the method was studied by varying its percent concentration from $0.5-3.0 \%(\mathrm{w} / \mathrm{v})$ and its volume from 0.5 $3.5 \mathrm{~mL}$. The maximum absorbance was found with $2.0-2.5 \mathrm{~mL}$ of $1 \%$ Triton X-100. Hence $2.0 \mathrm{~mL}$ of $1 \%$ Triton $\mathrm{X}-100$ was used for further studies. 


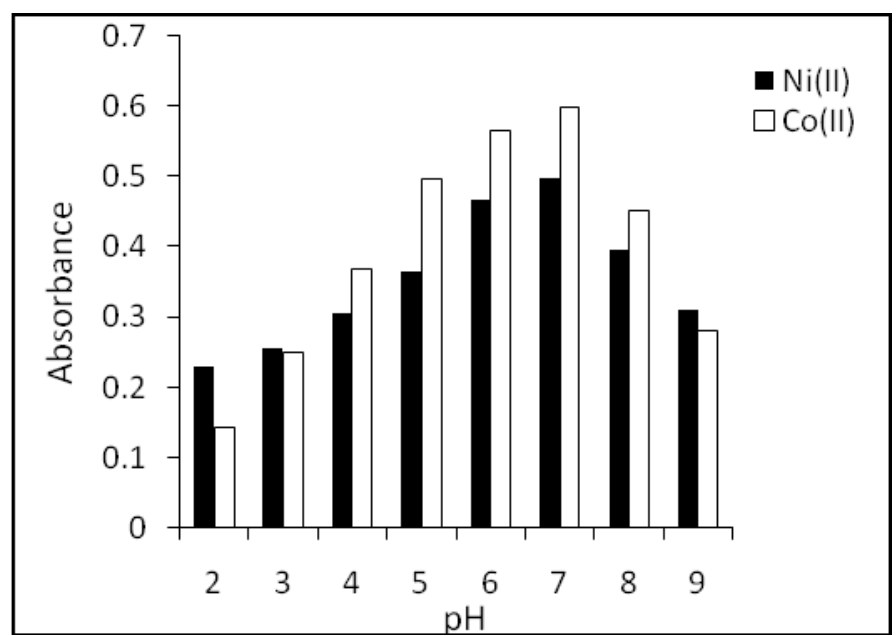

Figure 2. Effect of $\mathrm{pH}$ on the change in the absorbance of Co (II) and Ni (II)-ARS complexes.

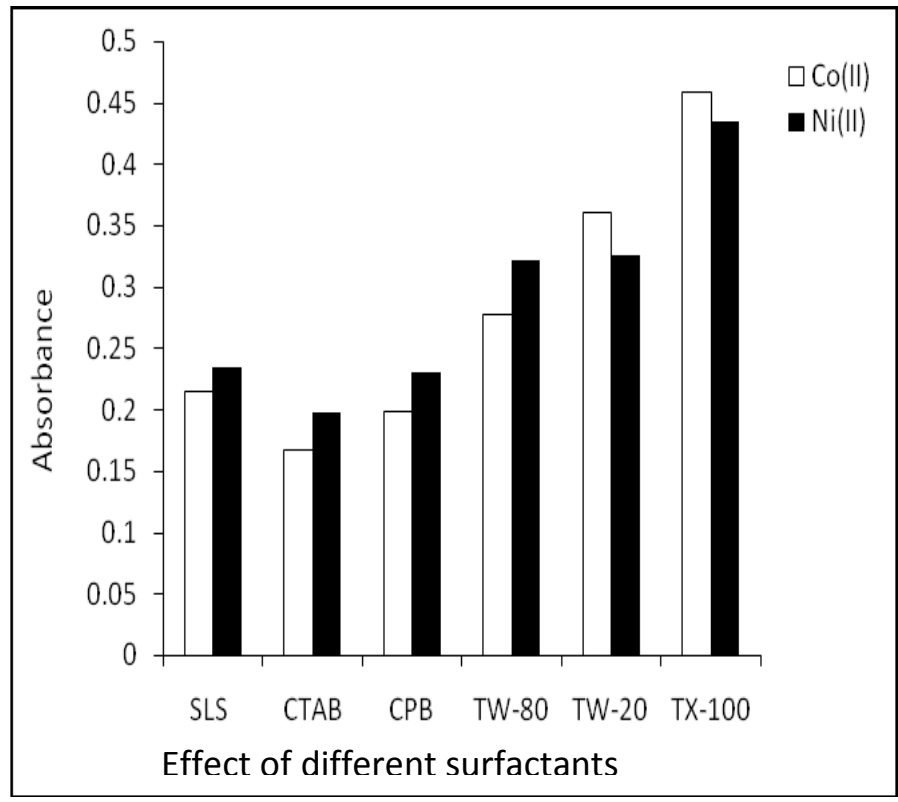

Figure 3. Effect of surfactants on complex formation of Co (II) and Ni (II).

\section{Derivative Spectra:}

First order derivative spectra of Co (II) and Ni (II) complexes were studied. Calibration graphs for first derivative spectra were obtained by using the zero-cross over technique. Two sets of mixtures were studied: one with increasing amounts of Co (II) from 0.293- 4.124 $\mu \mathrm{g} / \mathrm{mL}$ at constant concentration of $\mathrm{Ni}$ (II) and a second with increasing amounts of Ni (II) from $0.291-4.676 \mu \mathrm{g} / \mathrm{mL}$ at constant concentration of Co (II). The height $h_{2}$ and $h_{1}$ in the first derivative spectrum of mixture (See Figures 4 and 5) at wavelengths $546.0 \mathrm{~nm}$ and 
$549.0 \mathrm{~nm}$ is proportional to the nickel and cobalt concentrations, respectively. The calibration graph for $\mathrm{Ni}$ (II) and Co (II) was obtained by plotting absolute value of $\Delta \mathrm{h}$ against the concentration of $\mathrm{Ni}$ (II) and $\mathrm{Co}$ (II).

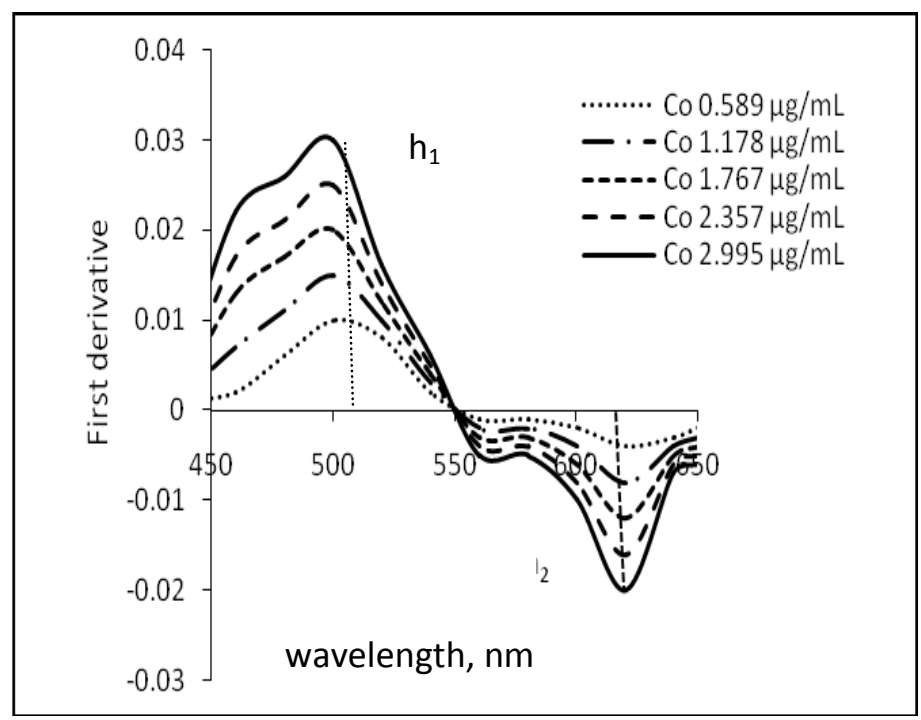

Figure 4. First order derivative spectra of solutions containing fixed concentration of Nickel $1.172 \mu \mathrm{g} / \mathrm{ml}$ and different concentration of Cobalt.

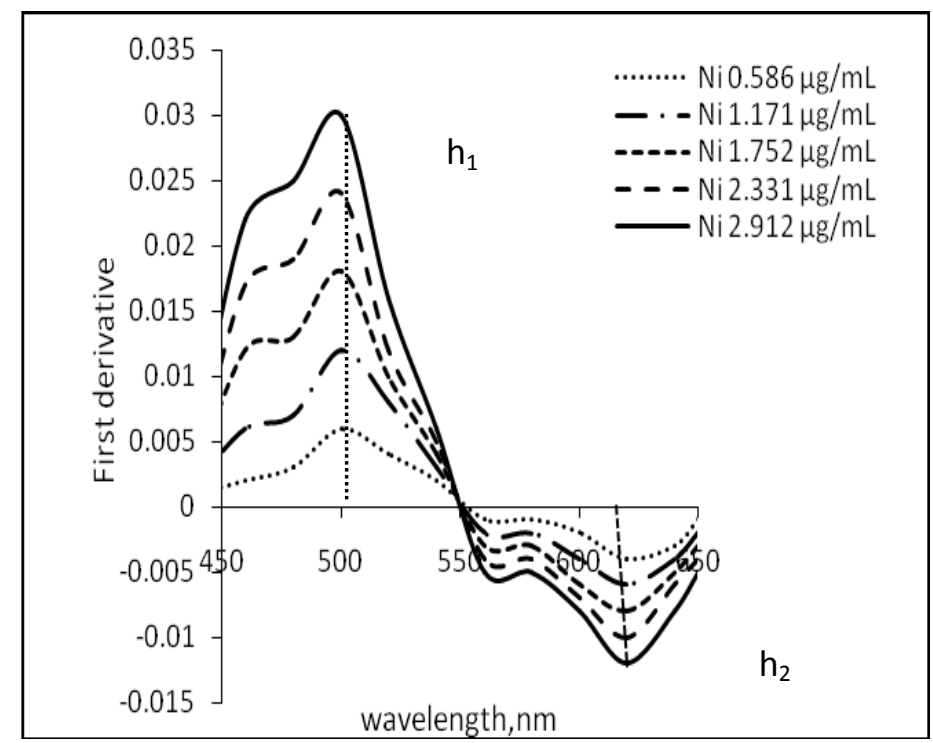

Figure 5. First order derivative spectra of solutions containing fixed concentration of Cobalt $0.883 \mu \mathrm{g} / \mathrm{ml}$ and different concentration of Nickel. 
Statistical Analysis of Results:

Various statistical parameters were calculated for $\mathrm{Co}$ (II) and $\mathrm{Ni}$ (II) with first order derivatives. The calibration graphs obtained by recommended methods were linear over a range of $0.293-4.124 \mu \mathrm{g} / \mathrm{mL}$ for cobalt in the presence of $1.172 \mu \mathrm{g} / \mathrm{mL}$ of nickel and 0.291 $4.676 \mu \mathrm{g} / \mathrm{mL}$ for the nickel in the presence of $0.883 \mu \mathrm{g} / \mathrm{mL}$ cobalt (Table 1). The values of correlation coefficients and intercepts on the axes indicate the good linearity of all the calibration graphs and correspondence to Beer's law for the first derivative measurements Also it can be seen that the first derivative values of cobalt and nickel complexes at 549 and $546 \mathrm{~nm}$, respectively, have a good precision due to lower values of RSD.

Table 1. Statistical analysis for the simultaneous determination of nickel and cobalt.

\begin{tabular}{|l|l|l|l|l|l|l|}
\hline Metal & $\begin{array}{l}\text { Order of } \\
\text { derivative }\end{array}$ & $\lambda(\mathrm{nm})$ & Regression Equation & $\mathrm{r}^{2}$ & $\begin{array}{l}\text { Linear range } \\
(\mu \mathrm{g} / \mathrm{m} \mathrm{L})\end{array}$ & R.S.D \\
\hline $\mathrm{Ni}(\mathrm{II})$ & $\mathrm{I}^{\text {st }}$ & 546.0 & $\mathrm{Y}=0.014 \mathrm{x}+0.001$ & 0.999 & $0.291-4.676$ & 0.66 \\
\hline $\mathrm{Co}(\mathrm{II})$ & $\mathrm{I}^{\text {st }}$ & 549.0 & $\mathrm{Y}=0.016 \mathrm{x}+0.002$ & 0.999 & $0.293-4.124$ & 0.780 \\
\hline
\end{tabular}

Interference Analysis

The effect of various diverse ions on the absorbance of a solution containing $0.5 \mu \mathrm{g} / \mathrm{mL}$ each of nickel and cobalt was studied. An ion was considered to interfere when its presence produced a variation in the absorbance of the sample greater than $5 \%$. Among the anions examined I- $\mathrm{Br}^{-}, \mathrm{Cl}^{-}, \mathrm{CO}_{3}{ }^{2-}, \mathrm{SO}_{3}{ }^{2-}, \mathrm{SO}_{4}{ }^{2-}, \mathrm{NO}^{3-}, \mathrm{IO}^{3-}, \mathrm{NO}_{2}^{-}, \mathrm{SCN}^{-}$, acetate, thiosulphate did not interfere at concentrations 1000 times higher than those of the analytes but ethylenediamine tetraacetate and oxalate ions interfered strongly. Among the cations $\mathrm{Hg}^{2+}$, $\mathrm{Cd}^{2+}, \mathrm{Cu}^{2+}$, and $\mathrm{Fe}^{2+}$ were masked with $1.0 \mathrm{~mL}$ of $5 \%$ sodium fluoride solution. $\mathrm{Bi}^{2+}$ and $\mathrm{Pb}^{2+}$ were masked with $2.0 \mathrm{~mL}$ of $1 \mathrm{M}$ sodium citrate solution.

\section{Application of the Method}

The proposed method has successfully been applied for Co (II) and Ni (II) determination. Several spiked samples were prepared by adding aliquots of Nickel and Cobalt solutions to river and tap water samples. The results are given in Table 2.

Table 2. Determination of nickel and cobalt in different real samples.

\begin{tabular}{|c|c|c|c|c|}
\hline \multirow{3}{*}{ Sample } & \multicolumn{3}{|c|}{ Concentration, $\mu \mathrm{g} / \mathrm{mL}$} & \\
\hline & \multicolumn{2}{|c|}{ Spiked } & \multicolumn{2}{|c|}{ Found } \\
\hline & Nickel & Cobalt & Nickel & Cobalt \\
\hline Tap water* & 2.916 & 2.996 & 2.918 & 2.998 \\
\hline Tap water** & 1.171 & 1.178 & 1.172 & 1.181 \\
\hline $\begin{array}{l}\text { Ganga river Water } \\
\text { or (Ganga jal) }\end{array}$ & 1.171 & 1.178 & 1.173 & 1.174 \\
\hline
\end{tabular}




\section{Conclusion}

The proposed method offers significant advantages over conventional methods because of its speed and ease of operation. This method works without the need of preconcentration or extraction steps. Thus, the inherent errors involved in these time-consuming steps using toxic and carcinogenic organic solvents are avoided, and determination in aqueous phase using micellar system makes the procedure eco-friendly. The proposed derivative spectrophotometric method has comparable sensitivity with a low detection limit. Moreover, low cost of the instrument, easy handeling, lack of requirement for consumable and almost no maintenance have made spectrophotometry still a popular technique.

\section{References}

1. J. Daintith, 1996. Oxford Dictionary of Chemistry. Oxford, UK: Oxford University Press.

2. A. Sirko and R. Brodzik, Acta Biochimica Polonica, 2000, 47, 1189.

3. Chen, J.; Teo, K. C. Anal. Chim. Acta 2001, 434, 325.

4. Huang, Y. L.; Tsai, Y. F.; Lin, T. H. Anal. Sci. 1999, 15, 79.

5. Zendelovska, D.; Pavlovska, G.; Cundeva, K.; Stafilov, T. Talanta 2001, 54, 139.

6. Lin, P. H.; Danadurai, K. S. K.; Huang, S. D. J. Anal. At. Spectrom. 2001, 16, 409.

7. V.G. Rodriguez, J.M.C. Romero, J.M.F. Solis, J.P. Iglesias and H.M.S. Lago, Anal. Lett. 1994, 27, 1399.

8. H. Niwa, T. Yasui, T. Ishizuki, A. Yuchi, H. Yamada and H. Wada, Talanta, 1997, 45,349.

9. A.M. Bond and G.G. Wallace, Anal. Chem., 1982, 54, 1706.

10. A.M. Bond and G.G. Wallace, Anal. Chem., 1984, 56, 2085.

11. Lu, H.; Yin, X.; Mou, S.; Riviello, J. M. J. Liq. Chromatogr. Relat. Technol. 2000, 23, 2033.

12. Ding, X.; Mou, S.; Liu, K.; Yan, Y. J. Chromatgr., A 2000, 883, 127.

13. Ghoneim, M. M.; Hassanein, A. M.; Hammam, E.; Beltagi, A. M. Fresenius. J. Anal. Chem.,2000, 367, 378.

14. Opydo, J. Mikrochim. Acta 2001, 137, 157.

15. Reyes-Salas, E. O.; Dosal-Gomez, M. A.; Barcelo-Quintal, M. H.; ManzanillaCano, J. A. Anal. Lett. 2002, 35, 123

16. Zecca, L.; Tampellini, D.; Rizzio, E.; Giaveri, G.; Gallorini, M. J. Radioanal. Nucl. Chem 2001, 248, 129.

17. Lau, O. W.; Ho, S. Y. Anal. Chim. Acta 1993, 280, 269.

18. Eksperiandova, L. P.; Blank, A. B.; Makarovskaya, Y. N. X-Ray Spectrom. 2002, $31,259$.

19. V. Rigin, Anal. Chim. Acta, 1993, 283, 895.

20. L. E. Attah ,Global J.of Pure and Applied Sciences. 2009, 3, 357-363.

21. A. Praveen Kumar, P. Raveendra Reddy, and V. Krishna Reddy. Journal of Automated Methods and Management in Chemistry. 2007, 6.

22. V.Kaur, A. K. Malik, Neelam Verma, J.Chin Chem.Soc.2007,54,715-722. 


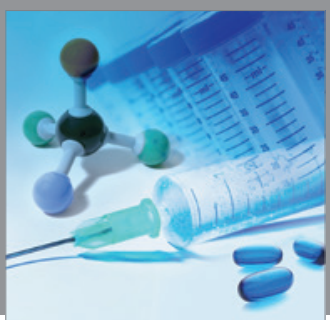

International Journal of

Medicinal Chemistry

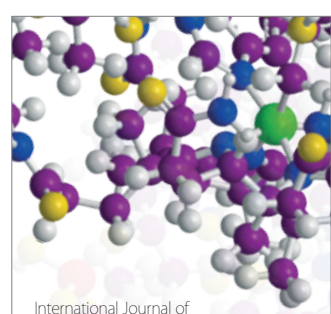

Carbohydrate Chemistry

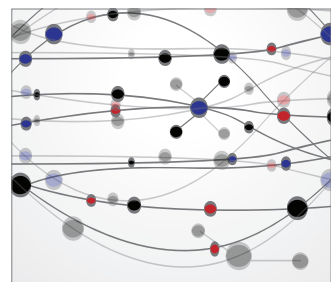

The Scientific World Journal
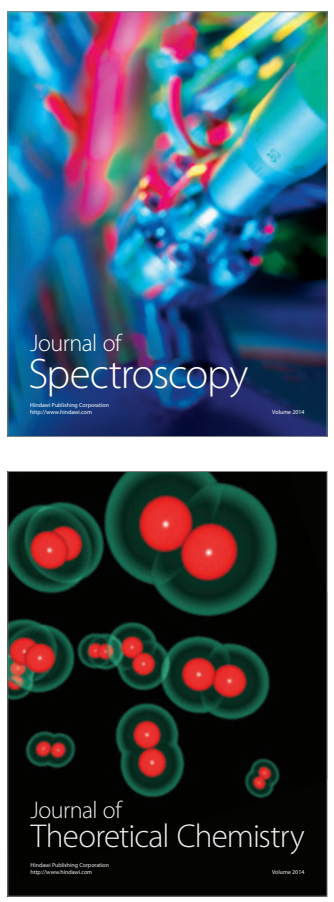
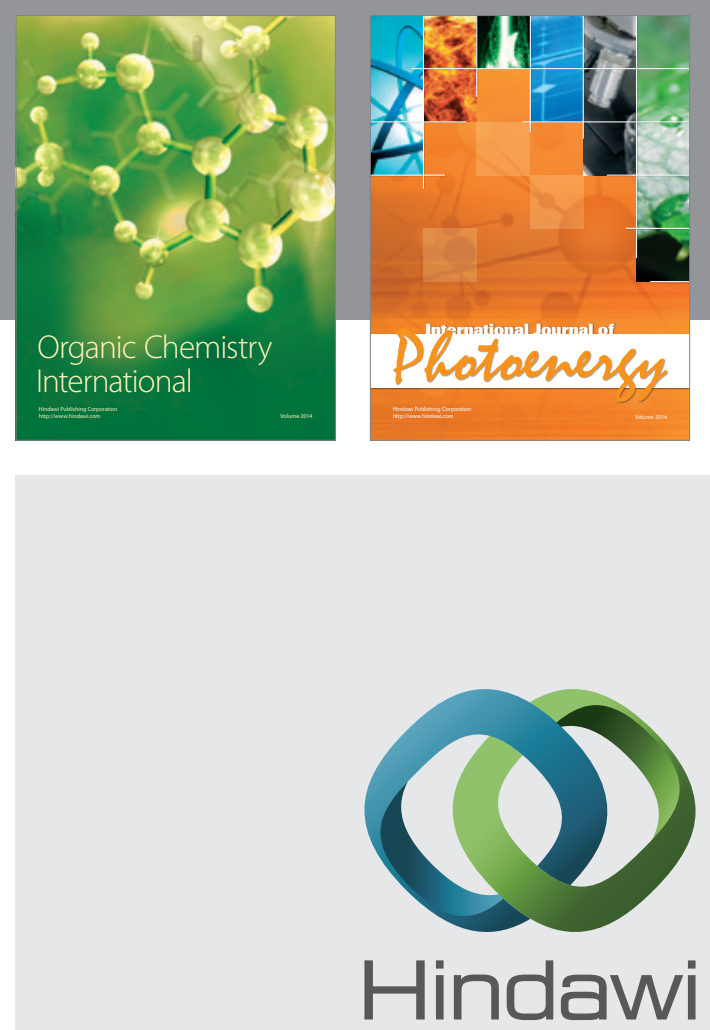

Submit your manuscripts at

http://www.hindawi.com
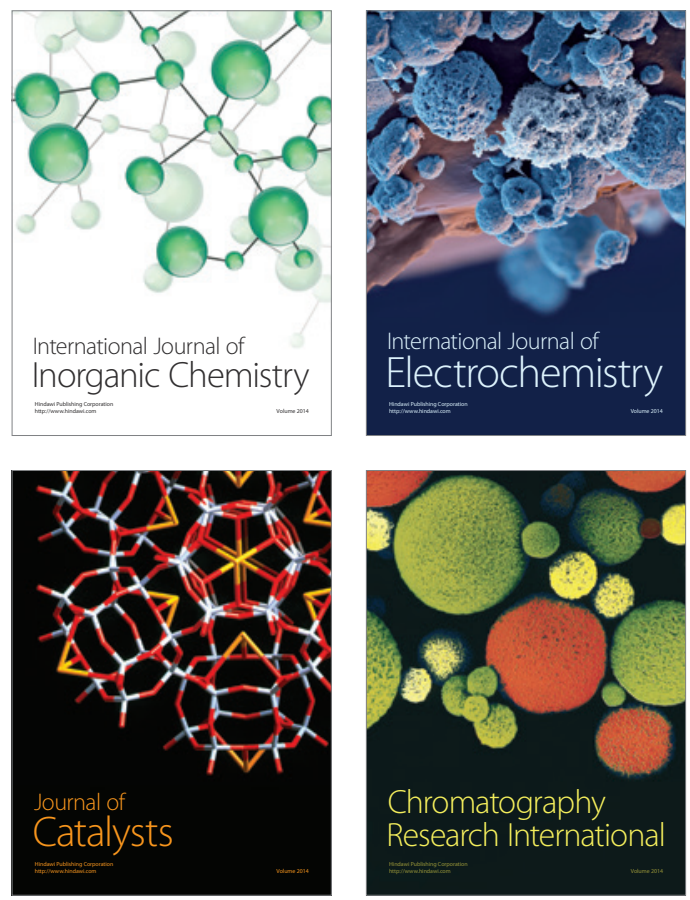
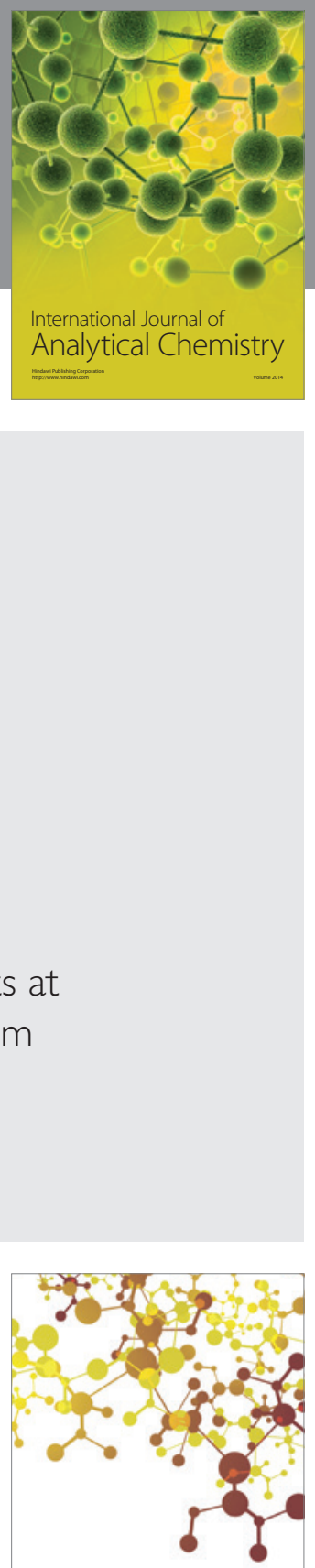

Journal of

Applied Chemistry
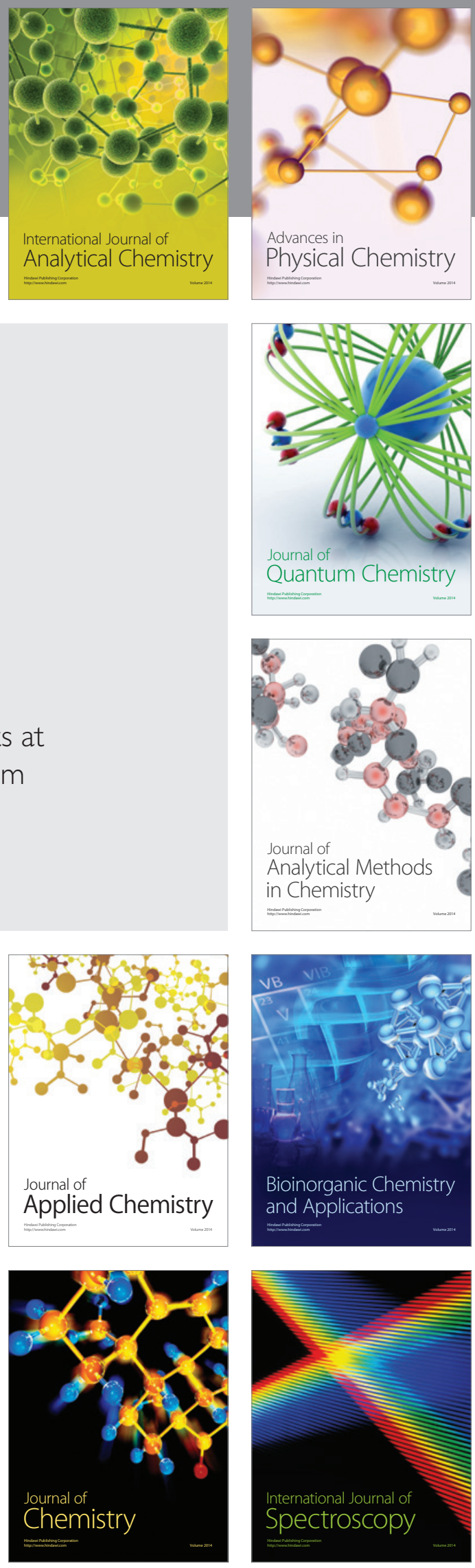